\title{
Configuração de Poder nas Organizações: o Caso da Embrapa
}

\author{
Miramar Ramos Maia Vargas
}

\begin{abstract}
ResUMO
O presente estudo usou a teoria das configurações de poder proposta por Mintzberg (1983) para perseguir dois principais objetivos: a) identificar quais os tipos de configurações que melhor representariam as relações de poder presentes em uma organização de pesquisa, segundo a percepção dos seus empregados e b) investigar possíveis relações existentes entre algumas variáveis e a percepção de poder que os empregados tinham da organização. A pesquisa foi conduzida na Empresa Brasileira de Pesquisa Agropecuária - Embrapa, com uma amostra de 1013 funcionários. Foi utilizada a Escala de Configuração do Poder Organizacional construída por Paz (1996), associada a uma versão reduzida da escala construída por Gordon et al. (1980) para medir o comprometimento sindical - uma das variáveis independentes da pesquisa. $\mathrm{Na}$ análise dos dados foram usadas estatísticas descritivas e inferenciais (regressão múltipla do tipo stepwise). Os resultados da pesquisa apontaram as configurações missionária e meritocracia como as que melhor representariam as relações de poder na Embrapa. As variáveis tempo de organização e cargo foram as melhores prognosticadoras dessas duas configurações de poder.
\end{abstract}

Palavras-chaves: poder nas organizações; comprometimento sindical; diagnóstico organizacional.

\begin{abstract}
This study used the theory of power proposed by Mintzberg (1983) to pursue two goals: a) to identify the best types of power configurations that represent the power relations in a research organization; b) to investigate whichever relations between some variables and the power perception that employees have of their organization. The research was carried out in the Empresa Brasileira de Pesquisa Agropecuária - Embrapa, Brazil, using a stratified random sample of 1013 employees. It were used the Organizational Power Configuration Scale (Paz, 1996) to measure five power configurations (dependent variables) and a short version of the Gordon et al. (1980) instrument to measure union commitment (one of the independent variables of the research). There were also another ten itens related to biographical and organizational employee data (independent variables). Descriptive and inferential statistics were used in the data analysis. The results of this research showed that missionary and meritocracy seemed to be the best configurations to explain the power relations in the surveyed organization. Two organizational variables - time of employment and held position - were found to be the best predictors of these two power configurations. Despite the exploratory nature of this study, it was observed that the typology proposed by Mintzberg (1983) proved to be useful for describing and explaining the power phenomena in the organizations.
\end{abstract}

Key words: power in organizations; union commitment; organizational analysis. 


\section{INTRODUÇĀO (*)}

O conhecimento do poder, seu uso e suas benesses não são assuntos novos na história da humanidade. Ao longo do tempo, todavia, o tema poder parece ter-se convertido em agente capaz de evocar sensações de desconforto nos indivíduos. Isso acontece porque, muitas vezes, ele tem sido associado a situações de intriga, de subjugação, de artimanhas políticas e outras situações não menos favoráveis.

Transportado ao ambiente das organizações, o tema não conseguiu perder as conotações pouco favoráveis que o cercam, a julgar pela discreta atenção com que vem sendo tratado por parte dos estudiosos e pesquisadores da área organizacional. É inegável que o exercício do poder é algo ativo e onipresente nas organizações; entretanto seu estudo continua grande desafio para muitos pesquisadores. Pfeffer (1981) fala da escassez de estudos e pesquisas na área e da dificuldade para reunir artigos e periódicos sobre o tema. Pagès et al. (1987) salientam que todos reconhecem a importância de se estudarem os problemas relacionados ao poder, mas que é extremamente difícil para o pesquisador ter acesso às organizações para investigar esses problemas.

Segundo Pfeffer (1981), o estudo do poder tem sido negligenciado por várias razões, como estas: 1) o próprio conceito de poder já é problemático dentro da maior parte da literatura em ciências sociais; 2) embora o poder seja importante, existem outras perspectivas competindo com ele na compreensão da tomada de decisão organizacional e 3) o conceito de poder também é problemático, quando se leva em consideração o processo de socialização dos gerentes e a prática da administração, em função das implicações e conotações que acompanham o tema.

Apesar da reserva com que o assunto ainda é muitas vezes tratado, é importante compreender as relações de poder que existem em uma organização. Entre outros benefícios, as relações de poder, quando bem administradas, podem desempenhar importante papel como agentes mediadores na prevenção e resolução de conflitos, assegurando a manutenção do equilíbrio e do crescimento organizacional. É possível também, com o estudo das relações de poder existentes, traçar-se um perfil da organização com benefícios diretos para várias áreas, entre elas a tomada de decisão organizacional.

Existem na literatura vários modelos que procuram mostrar as relações de poder presentes nas organizações. Neste estudo, a autora optou por aplicar o modelo proposto por Mintzberg (1983) para identificar as relações de poder presentes em uma organização de pesquisa. Uma rápida síntese desse modelo se faz necessá- 
ria, a fim de que se compreenda melhor os resultados alcançados com a pesquisa e suas implicações para a organização estudada.

\section{O Estudo das Relaçóes de Poder segundo Mintzberg}

\section{Peculiaridades do Modelo}

No modelo proposto por Mintzberg (1983) para o estudo do poder nas organizações, dois aspectos chamam atenção pela maneira diferente com que foram tratados em relação à literatura clássica existente sobre o tema. $\mathrm{O}$ primeiro aspecto se reporta ao conceito de poder dado pelo autor. A literatura deixa claro que conceituar poder não é fácil tarefa. Somando-se à própria complexidade do tema, outros termos tais como autoridade e influência costumam estar envolvidos em sua definição. Peabody (apud Bacharach e Lawler, 1982) menciona que existem três abordagens para se conceituar autoridade e influência: alguns autores tendem a igualar esses conceitos; outros tendem a igualar poder com influência e estabelecer que autoridade é um caso especial de poder e, finalmente, outros vêm autoridade e influência como dimensões diferentes. Diversos autores buscaram conceituar o termo poder, mas Bacharach e Lawler (1982) lembram que a maior parte dos conceitos de poder são baseados na clássica definição dada por Max Weber, em 1947, de que o poder é a probabilidade de uma pessoa exercer a sua vontade a despeito de qualquer resistência. Quase todos os teóricos que escreveram sobre poder, segundo Bacharach e Lawler (1982), expressam concordância com essa definição mais ampla, embora cada um, em particular, tenha adicionado as suas próprias perspectivas ao conceito. Mintzberg (1983) preferiu abster-se de uma discussão maior de conceitos abstratos, definindo poder como sendo simplesmente a capacidade de afetar os resultados organizacionais.

O segundo aspecto que chama atenção na obra de Mintzberg (1983) é o fato de o autor não ter privilegiado nenhum dos dois níveis de análise, psicológico e sociológico, em que geralmente se divide o estudo do poder nas organizações. Essa distinção que há entre as duas correntes de pesquisa geralmente se reflete na ênfase dada pelos psicólogos organizacionais no entendimento do poder como fenômeno funcional, enquanto os sociólogos organizacionais o focalizam como fenômeno estrutural. Trabalhando com perspectiva mais abrangente, Mintzberg (1983) parece ter percebido que essa dualidade de enfoques com relação ao estudo do poder tenderia a se tornar cada vez menos saliente com o passar do tempo. Isso se comprovaria, mais de uma década depois, com o trabalho de Pettigrew e McNulty (1995): os autores defendem a idéia de que o poder tem um aspecto macro ou estrutural e um aspecto micro ou relacional. A análise estrutural do 
poder direcionaria o analista para a posse e controle das fontes de poder tais como posição, recompensas, sanções e informação. $\mathrm{O}$ tratamento relacional do poder (que os dois autores definem como influência) levaria o analista a explorar a vontade e a habilidade em se criar e usar as fontes de poder potencialmente disponíveis. Segundo Pettigrew e McNulty (1995) as análises mais recentes de poder (Frost, 1986; House, 1988; Krackhardt, 1990; Brass e Burkhardt, 1993) têm procurado manter equilíbrio analítico entre a forma estrutural e relacional do poder.

\section{Base do Modelo}

Mintzberg (1983) trata a estrutura e o fluxo do poder dentro e em torno das organizações. $\mathrm{O}$ autor busca, primeiramente, compreender os elementos básicos do jogo chamado poder organizacional, especificamente quem são os seus jogadores ou influenciadores, quais são os meios ou sistemas de influência que eles usam para ganhar poder, e quais são os produtos que resultam dos seus esforços. A seguir, todos esses elementos são reunidos para descrever várias configurações básicas do poder organizacional e, finalmente, o autor tenta ver como se pode usar essas configurações para compreender melhor o comportamento das organizações.

\section{O Elenco de Jogadores (ou Influenciadores)}

Mintzberg (1983) distingue dois tipos de influenciadores que interferem na vida das organizações: os externos e os internos. Os indivíduos que não são empregados da organização, mas que usam as suas bases de influência para tentar afetar o comportamento dos empregados, são os influenciadores externos, que formam a coalizão externa. $\mathrm{O}$ autor identifica cinco grupos principais de influenciadores externos: proprietários, associados (fornecedores, clientes, sócios e competitores), as associações de empregados, os sindicatos e os vários públicos que cercam todos eles.

Os influenciadores internos são os empregados da organização que possuem voz ativa, ou seja, são as pessoas encarregadas de tomar decisão e executar ações em base regular ou permanente. Eles formam a coalizão interna. A partir do momento em que a organização é desenhada, ou seja, quando o dirigente da organização delega competência para outros indivíduos, surge o problema do controle e, com ele, emergem sistemas de influência que podem ser usados pelos vários participantes da coalizão interna. Mintzberg (1983) identifica quatro sistemas básicos de influência: sistema de autoridade, sistema de ideologia, sistema de especialistas e sistema político. A forma pela qual cada um desses sistemas é usado dentro da organização e no que resulta a mistura desses quatro sistemas é o 
que determina o tipo de coalizão interna que a organização irá ter. Em cada parte da organização um dos sistemas de influência pode emergir como o mais importante; entretanto os grupos raramente compartilham o poder de forma igualitária dentro da coalizão interna. Dependendo das circunstâncias, um grupo geralmente assume a posição de maior importância e, quando isso acontece, o sistema de influência favorecido por aquele grupo emerge como o mais forte. Isso leva ao surgimento de cinco tipos de coalizões internas: 1) coalizão interna personalizada; 2) coalizão interna burocrática; 3 ) coalizão interna ideológica; 4) coalizão interna profissional e 5) coalizão interna politizada.

A coalizão externa pode exercer amplo poder com respeito à coalizão interna. Esse poder pode ser expresso em termos de três tipos básicos de coalizões externas, listadas em ordem decrescente de poder: coalizão externa dominadora, coalizão externa dividida e coalizão externa passiva. $O$ tipo de coalizão externa que existe em torno da organização afeta, em consideráveis proporções, o tipo de coalizão interna que ela desenvolve. Uma coalizão externa dominadora tende a enfraquecer a coalizão interna. A coalizão externa dividida tende a politizar a coalizão interna, e uma coalizão externa passiva tende a fortalecer a coalizão interna, geralmente no nível do dirigente da organização; entretanto o autor faz a ressalva de que, seja qual for a coalizão externa, é mediante os esforços da coalizão interna que a organização funciona e estabelece os seus objetivos. Ela é o coração do sistema do poder organizacional.

\section{As Configurações de Poder}

Mintzberg (1983) reúne e sintetiza todos os elementos do poder que existem dentro e em torno das organizações, combinando de várias maneiras os influenciadores das coalizões interna e externa, os meios do sistema de influência que eles usam, os tipos de coalizões interna e externa que eles formam e os objetivos do sistema que resulta. A essas combinações resultantes é dado o nome de configurações de poder. $\mathrm{O}$ autor identifica seis configurações de poder, que ele considera como tipos puros, que parecem melhor caracterizar os estados mais comuns de equilíbrio de poder encontrados nas organizações. Essas configurações foram assim denominadas: instrumento, sistema fechado, autocracia, missionária, meritocracia e arena política.

. Configuração de Poder Instrumento. A organização serve a um influenciador externo dominador (ou a um grupo deles agindo em conjunto). Os empregados são induzidos a contribuir com os seus esforços, tendo pouca oportunidade para atuar nos jogos do poder. Esse tipo de configuração tende a emergir, quando a organização vivencia um poder externo, focalizado e organizado tipicamente em torno de uma dependência crítica ou de uma prerrogativa le- 
gal, que emana de um influenciador externo com objetivos claros e operacionais.

. Configuração de Poder Sistema Fechado. Ela se assemelha à configuração de instrumento, mas a diferença fundamental é que não enfrenta um poder focalizado dentro do seu ambiente, mas um conjunto de influenciadores externos dispersos e desorganizados (coalizão externa passiva). Essa configuração tende a aparecer em organizações mais estabelecidas, tipicamente as grandes organizações que operam em ambientes simples e estáveis, com trabalhadores sem especialização e influenciadores externos dispersos.

. Configuração de Poder Autocracia. A autocracia também enfrenta uma coalizão externa passiva, mas desenvolve um tipo bem diferente de coalizão interna. Todo o poder está focalizado no dirigente da organização, que a controla pessoalmente. Essa forma rígida de controle significa uma ausência virtual de jogos políticos; os empregados ou expressam uma lealdade ao dirigente ou vão embora. A autocracia persegue e, se necessário, maximiza qualquer objetivo que o dirigente deseje. As autocracias tendem a ser: organizações pequenas e pouco visíveis; organizações novas ou antigas que sejam dirigidas por seus fundadores; organizações que operam em ambientes simples e dinâmicos, algumas vezes com líderes fortes ou enfrentando crises severas.

. Configuração de Poder Missionária. A missionária é tão dominada por uma ideologia, que a sua coalizão externa também é passiva. A forte ideologia serve para amarrar a coalizão interna em torno dos seus objetivos ideológicos e permite, também, que os seus membros sejam confiáveis para tomar decisões, uma vez que todos eles compartilham as mesmas crenças e tradições. Dificilmente os jogos políticos se desenvolvem nessa configuração. Todos os esforços são devotados para perseguir o objetivo de preservar, expandir e/ou aperfeiçoar a missão da organização. A missionária tende a emergir quando a organização vivenciou uma liderança carismática no passado e, talvez, uma história importante, passando a desenvolver fortes tradições em torno de uma missão clara, distinta e atrativa para os seus membros.

. Configuração de Poder Meritocrática. A meritocracia focaliza o seu poder sobre os seus especialistas, desenvolvendo uma coalizão interna profissional. A presença de diferentes tipos de especialistas geralmente propicia boa dose de atividade política. Dessa forma, a coalizão externa pode ser mais bem descrita como passiva, embora ela pareça estar dividida. Devido ao seu treinamento, os especialistas possuem muitas oportunidades para a rotatividade e, por isso, a sua lealdade à organização é um fator fraco. A condição chave que faz surgir a meritocracia é a necessidade de a organização desempenhar um trabalho complexo, o qual requer alto nível de especialização na sua coalizão interna. 
. Configuração de Poder Arena Política. A arena política é caracterizada por conflito, tanto na coalizão externa, que é dividida, quanto na coalizão interna, que é politizada. Algumas arenas políticas são caracterizadas por intenso conflito, o qual dura pouco tempo (senão a organização não sobrevive), enquanto outras são caracterizadas por um tipo de conflito mais moderado. Embora a arena política pareça uma disfunção - a harmonia permite melhor que as organizações atinjam as suas missões do que o conflito - ela não é, necessariamente, uma aberração. A arena política pode servir como estágio funcional e, na verdade, necessário na transição de uma configuração de poder para outra. Ela emerge quando uma organização vivencia um desafio à sua ordem de poder existente, ou aquela existente entre os seus influenciadores e, também, quando há forças equilibradas e irreconciliáveis dentro da organização.

Os sistemas de poder e de objetivos dentro e em torno das organizações estariam em estado de equilíbrio dinâmico. As configurações de poder têm de ser vistas como instáveis. Cada uma permanece estável apenas sob certas condições, ou seja, quando essas condições as apóiam; elas se desestabilizam assim que essas condições se alteram.

\section{A Transição entre Configurações}

Mintzberg (1983) esclarece que a literatura sobre padrões de transição entre tipos de organizações é geralmente referida como teoria de estágios de desenvolvimento. Essa teoria considera que certas forças intrínsecas fazem com que as organizações passem naturalmente de um tipo para outro, através de uma série de estágios que vão ocorrendo à medida que elas crescem, se fortalecem e elaboram suas estruturas.

Especificamente, a maioria dos autores descreve toda ou partes de uma seqüência de três estágios, que vai desde uma estrutura simples, passando para uma máquina burocrática e indo para uma forma divisionalizada. Nenhum autor discorda de que essa seqüência seja inevitável. Alguns proclamam que certas formas de organizações tendem a se estabelecer em determinados estágios e aí permanecem; outras quebram essa seqüência, pulando algum estágio ou revertendo a algum estágio anterior. De maneira geral, entretanto, os autores concordam que, em todos os estágios da teoria de desenvolvimento organizacional, certos padrões são mais naturais que outros, ou seja, têm maior plausibilidade de ocorrer.

Mintzberg (1983) acredita que essa série de três estágios seria uma seqüência natural, mas incompleta. Ela seria consistente com o que a literatura fala sobre estrutura organizacional, mas ela incluiria muito pouco do que já se sabe sobre o poder nas organizações. Ela lida com o crescimento, mas não diz nada sobre o 
processo de extinção ou desaparecimento da organização. Essa seqüência apresenta um ciclo de vida que termina na maturidade, desconsiderando o envelhecimento e a morte da organização como se esses dois estágios não fizessem parte do seu ciclo de vida. Procurando cobrir essa lacuna, o autor faz uso das suas configurações de poder e propõe um modelo revisado de desenvolvimento organizacional, descrevendo um retrato mais completo dos ciclos de vida das organizações.

O modelo renovado dos estágios do desenvolvimento organizacional, proposto por Mintzberg (1983), sugere que as organizações nascem como autocracias. Aquelas que sobrevivem tendem a fazer uma transição ou para instrumento ou para missionária, o que seria equivalente ao estágio da adolescência ou de um rápido desenvolvimento, apesar de que algumas vão diretamente para o estágio de maturidade das configurações de sistema fechado ou de meritocracia. As organizações do tipo instrumento e missionária que conseguem sobreviver geralmente se tornam sistemas fechados ou meritocracias. Todas essas transições, exceto de autocracia para missionária, freqüentemente envolvem um estágio intermediário de arena política, na forma de confrontação e/ou alianças. Os sistemas fechados e as meritocracias tendem a perdurar por um considerável período de tempo, em parte por causa da capacidade de se renovarem através da forma de confrontação da arena política. Mas essas configurações tendem gradualmente a se politizarem, emergindo, eventualmente, um estágio de declínio organizacional sob a forma de arena política, a que o autor chama de organização politizada. Apesar de que uma total renovação da organização seja possível, mediante a regressão à forma de autocracia, para começar novo ciclo de vida, é muito mais provável que a organização politizada seja caminho sem retorno; em sua última conseqüência, pelo surgimento de uma completa arena política, leva à morte da organização.

\section{Objetivos da Pesquisa}

Tomando por base a teoria das configurações de poder de Mintzberg (1983), este estudo buscou atingir dois grandes objetivos:

. Identificar quais os tipos de configurações que melhor representam as relações de poder presentes na organização pesquisada, segundo a percepção dos seus empregados.

. Investigar possíveis relações existentes entre algumas variáveis e a percepção de poder que os empregados têm da organização. 


\section{Descriçāo das VariáVEIS}

A pesquisa englobou duas categorias distintas de variáveis. A primeira categoria, denominada variáveis dependentes, foi formada pelos cinco fatores presentes na Escala de Configuração do Poder Organizacional construída por Paz (1996), com base nas seis configurações de poder propostas por Mintzberg (1983). É importante salientar que, na validação do seu instrumento, Paz (1996) encontrou quatro das seis configurações de poder originalmente propostas por Mintzberg (1983): autocracia, sistema fechado, missionária e meritocracia. As outras duas configurações citadas pelo autor - instrumento e arena política - acabaram por se agrupar em um único fator, a que Paz (1996) deu o nome de configuração de poder instrumento partidário. Dessa maneira, as variáveis dependentes desta pesquisa ficaram sendo: autocracia, sistema fechado, missionária, meritocracia e instrumento partidário.

A segunda categoria, denominada variáveis independentes, foi formada por 12 variáveis: gênero, idade, escolaridade, cargo, lotação, tempo de organização, chefia (o empregado ocupava ou não cargo de chefia), tempo de chefia, filiação sindical (o empregado era ou não filiado ao sindicado da organização), atividade no sindicato (o empregado exerce ou já exerceu alguma atividade no sindicato da organização), tempo de atividade no sindicato e comprometimento sindical.

$\mathrm{Na}$ escolha das variáveis independentes, além das características biográficas dos respondentes da pesquisa, procurou-se investigar, também, outras características que poderiam influir na percepção de poder que os empregados tinham da organização. No caso específico do comprometimento sindical, por exemplo, a idéia foi investigar possíveis associações entre essa variável e as relações de poder existentes. É sabido que os empregados buscam alguma forma de controle sobre as decisões e ações da organização a que pertencem. Como eles não conseguem fazer isso individualmente, procuram unir-se a um sindicato, mediante o qual terão maiores chances de provocar alguma mudança na organização.

\section{Metodologia}

A pesquisa foi realizada na Empresa Brasileira de Pesquisa Agropecuária Embrapa, empresa pública vinculada ao Ministério da Agricultura e do Abastecimento, com sede em Brasília, DF, e unidades de pesquisa localizadas em todo o território nacional. 
Foi utilizada uma amostra aleatória de $35,5 \%$ da população alvo. A amostra final, formada por 1013 empregados, ficou caracterizada da seguinte forma: a) sexo: predominância de respondentes do sexo masculino, $68,4 \%$; b) idade: concentração maior de respondentes na faixa etária entre 31 a 40 anos, 35,3\%; c) escolaridade: nível educacional elevado, sendo $24 \%$ dos empregados com segundo grau, $27,3 \%$ com curso superior, $7,6 \%$ com especialização, $26,3 \%$ com mestrado e 14,8\% com doutorado; d) lotação: $87 \%$ dos empregados estavam lotados nas unidades de pesquisa da Embrapa; e) cargo: a maior parte dos respondentes, $61,4 \%$, ocupava cargos do grupo ocupacional Suporte à Pesquisa, responsável pela atividade-meio da organização; f) tempo de organização: a maior parcela de respondentes, 25,3\%, trabalhava há mais de 20 anos na Embrapa; g) chefia: 53,6\% nunca exerceu nenhum cargo de chefia na organização; h) tempo de chefia: dos que exerciam ou já exerceram cargo de chefia, a maior parcela, 19,3\%, relatou estar exercendo ou ter exercido um cargo por um período superior a 4 anos; i) filiação sindical: a grande maioria, 87,8\%, era filiada ao sindicato da Embrapa; j) atividade sindical: apenas $17,4 \%$ relataram ter exercido ou estar exercendo alguma atividade no sindicato da empresa; $\mathrm{k}$ ) tempo de atividade sindical: $9,3 \%$ dos empregados exerceram ou estão exercendo alguma atividade no sindicato por um período entre 1 a 2 anos.

\section{INSTRUMENTO}

Foi utilizado um questionário com base na conjugação de dois instrumentos. $\mathrm{O}$ primeiro, desenvolvido por Paz (1996), foi construído em torno das configurações de poder propostas por Mintzberg (1983), com 40 itens para serem respondidos por meio de uma escala do tipo Likert, de cinco pontos. Foram encontrados cinco fatores, que representavam as seguintes configurações de poder: autocracia, sistema fechado, missionária, meritocracia e instrumento partidário, sendo que todos os fatores apresentaram alfas de Cronbach acima de 0.70 . O segundo instrumento, adaptado por Bastos (1994), foi desenvolvido com o objetivo de avaliar o grau de comprometimento dos empregados com um sindicato (uma das variáveis independentes da pesquisa), e era composto por 10 itens para serem respondidos por meio de uma escala do tipo Likert, de sete pontos. $\mathrm{O}$ instrumento era formado por um único fator denominado comprometimento sindical, com alfa de Cronbach igual a 0.88 . 


\section{ANÁlise dos Dados}

Os dados da pesquisa foram analisados mediante o pacote estatístico Statistical Package for the Social Sciences - SPSS, versão 5.01 para windows. Foram feitas estatísticas descritivas para as respostas obtidas no conjunto total do questionário, ou seja, para os 60 itens ( 40 do instrumento de configurações de poder, 10 do instrumento de comprometimento sindical e 10 dos dados biográficos e funcionais dos respondentes), calculando-se medidas de tendência central, de dispersão e distribuições de freqüência. Com relação aos dois instrumentos que compunham o questionário - configurações de poder e comprometimento sindical - foram calculados a média, o desvio padrão e o erro padrão das respostas fornecidas pelos respondentes. Foram calculados, também, os coeficientes de correlação bivariada (correlações de Pearson), para se verificar, entre as variáveis independentes, quais as que apresentavam correlações bivariadas significativas com as variáveis dependentes. Finalmente, foi realizada uma análise de regressão múltipla para se investigarem as relações existentes entre as variáveis independentes e a percepção de configurações de poder que os empregados tinham da organização.

\section{Resultados}

Com relação ao primeiro objetivo da pesquisa foi encontrado que as configurações missionária e meritocracia emergiram como as que melhor representariam as relações de poder existentes na Embrapa, obtendo as médias mais altas: 3,91 e 3,19 , respectivamente. A Figura 1 mostra um gráfico com as médias das cinco configurações de poder.

\section{Figura 1: Média dos Fatores das Configurações de Poder}

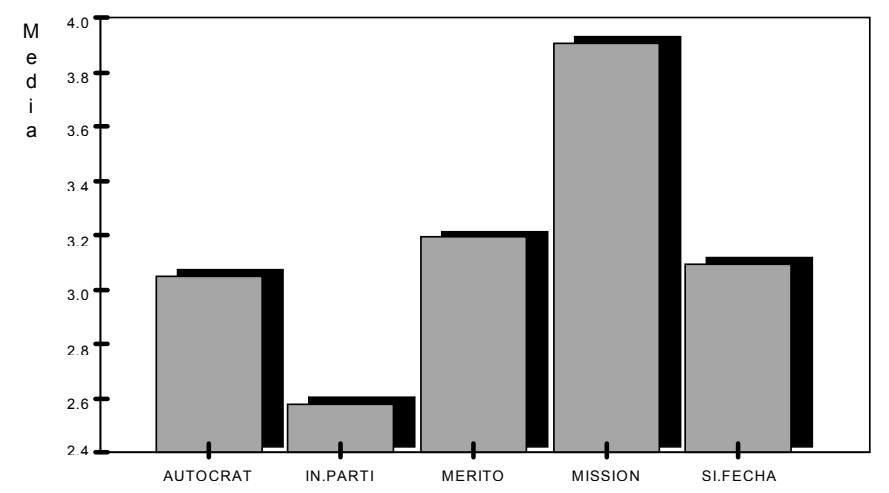


Quanto ao segundo objetivo da pesquisa, observou-se que as melhores prognosticadoras para as variáveis dependentes missionária e meritocracia, tipos de configurações que melhor representariam as relações de poder na Embrapa, foram, respectivamente, tempo de organização e cargo. Na análise de regressão entre a variável dependente missionária e a variável independente tempo de organização, foi observado que os empregados com mais tempo de serviço na Embrapa são os que percebem essa configuração como a mais aplicável à empresa. A Figura 2 apresenta um gráfico com as duas variáveis, permitindo uma visualização mais clara desse resultado.

\section{Figura 2: Configuração de Poder Missionária e Variável Tempo de Organização}

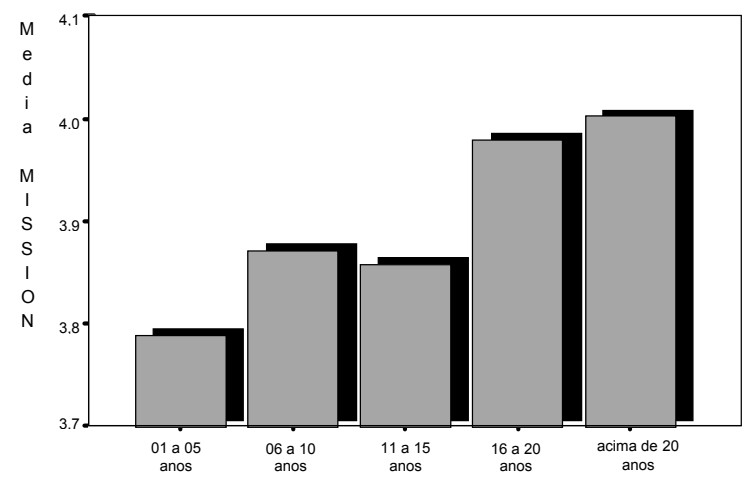

$\mathrm{Na}$ análise de regressão entre a variável dependente meritocracia e a variável independente cargo, foi observado que os empregados que ocupam cargos do grupo ocupacional Técnico-Científico (atividade-fim) percebem esse tipo de configuração de poder como menos aplicável à Embrapa do que os empregados que ocupam cargos do grupo ocupacional Suporte à Pesquisa (atividade-meio).

Uma avaliação global dos demais resultados obtidos com a análise de regressão indicou que algumas variáveis independentes se revelaram como prognosticadoras específicas de determinadas variáveis dependentes, sendo que outras foram comuns a mais de uma variável. Duas variáveis independentes, idade e sindical, não foram prognosticadoras de nenhuma das cinco variáveis dependentes. A variável independente comprometimento sindical apareceu como prognosticadora de todas as cinco variáveis dependentes, não como a melhor prognosticadora, mas contribuindo com diferentes percentuais para explicar a variância total de cada uma delas. 


\section{Discussão}

A rigor, uma organização como a Embrapa possui todas as características para apresentar uma configuração de poder do tipo meritocrática. O poder está concentrado nas mãos dos seus especialistas técnico-científicos, responsáveis pela execução da atividade-fim da empresa e sobre os quais repousa o pilar da organização - a pesquisa agropecuária. Além disso, a Embrapa se enquadra naquele elenco de organizações que, segundo a literatura, costuma quebrar a seqüência dos três estágios do desenvolvimento organizacional, por conseguir estabelecerse, desde o início, num estágio mais consolidado de desenvolvimento.

Como se interpretaria, então, o fato de os empregados da Embrapa terem atribuído a primeira média mais alta à configuração missionária e a segunda média à configuração meritocrática? Como explicar, também, a presença dessas duas configurações se, de acordo com a teoria proposta por Mintzberg (1983), as configurações missionária e meritocracia são menos prováveis de compatibilização, uma vez que a coalizão interna da primeira é dominada pelo sistema de ideologia, que prima por compartilhar crenças e ideais comuns, não havendo espaço para privilegiar esse ou aquele grupo, como no caso da meritocracia, cuja coalizão interna é dominada pelo sistema de especialistas? Na opinião desta autora, algumas hipóteses poderiam ser levantadas para explicar o fenômeno, as quais serão discutidas a seguir.

\section{A Embrapa como Organização Missionária}

A construção de uma ideologia, segundo Mintzberg (1983), atravessa três estágios. A discussão da Embrapa como organização missionária será feita tomandose por base esses estágios.

Estágio 1 - As Raízes da Ideologia. "Uma nova organização é criada juntando-se um líder fundador, uma missão singular a ser cumprida e o estabelecimento de um grupo".

A Embrapa foi criada em 1973 com uma missão importante - iniciar uma nova era na agricultura brasileira. A história relata que remonta ao tempo do Império os primeiros esforços no sentido de se organizar, em nível nacional, a pesquisa agrícola no Brasil. Todas as tentativas não lograram êxito, mesmo aquelas que incluíram medidas mais profundas, tomadas já na era da República. Isso teria acontecido, segundo os historiadores, porque todas esbarraram na indiferença quanto ao papel da pesquisa na modernização da agricultura. A Embrapa surgiria assim, com essa importante missão - a de mudar os rumos da agricultura brasileira por meio da geração de tecnologia e da implantação de um efetivo programa de 
controle e coordenação do sistema nacional de pesquisa agropecuária. A permanência de um mesmo líder, durante muitos anos, nos mais altos postos de direção da empresa teria contribuído, significativamente, para o cumprimento dessa missão.

Estágio 2 - O Desenvolvimento da Ideologia. “A organização desenvolve gradualmente sua própria história, criando hábitos e mitos que formam a base de uma tradição que os membros da instituição passam a compartilhar".

É possível que, após a implantação da Embrapa, o espírito de mudança e de compartilhamento de um novo ideal tenha contagiado todos aqueles que contribuíram para o crescimento da organização, quer no papel de seus dirigentes, quer no papel de simples empregados. Krackhardt e Kilduff (apud Ibarra e Andrews, 1993), relatam que grupos que entram na organização em um mesmo período de tempo tendem a compartilhar as mesmas idéias. Isso talvez explique a lealdade de muitos empregados que até hoje continuam na empresa. A pesquisa revelou que a maior parcela dos respondentes $(25,3 \%)$, possuía mais de 20 anos de serviço na organização, ou seja, estava desde a época da fundação da empresa. É possível, também, que esse mesmo sentimento ideológico, esse compartilhar de crenças explique o fato de ter sido a variável funcional tempo de organização a melhor prognosticadora da variável missionária, indicando que os empregados com mais tempo de serviço na Embrapa eram os que percebiam a configuração de poder do tipo missionária como mais aplicável à organização.

Estágio 3 - O Reforço da Ideologia. "Uma ideologia existente é reforçada através da identificação de novos membros com a organização e o sistema de crenças que essa possui”.

Aparentemente, os novos membros que se juntaram à Embrapa, depois da fundação, ter-se-iam identificado com a empresa e com o sistema de crenças que ela possuía à época, reforçando sua ideologia. Os resultados da pesquisa apontaram que tanto os mais antigos, com mais de 20 anos de serviço na organização, quanto os que entraram algum tempo depois, integrantes da faixa de 16 a 20 anos de serviço, percebiam a configuração missionária de poder como muito aplicável à Embrapa. Por outro lado, os resultados também indicaram que os empregados com menor tempo de serviço, integrantes da faixa de 01 a 05 anos, foram os que menos percebiam a Embrapa como organização missionária.

De acordo com Mintzberg (1983), uma configuração de poder do tipo missionária tende a aparecer nos primeiros anos de formação da organização, mais ou menos relacionada à fase da adolescência, durante a qual o crescimento ocorre e a maturidade se aproxima. A organização passaria, então, a atravessar novo estágio de desenvolvimento, com mudança de configuração de poder. Dessa forma, é possí- 
vel prever que, em futuro próximo, a configuração missionária não venha mais a ser apontada como uma das configurações que melhor representaria as relações de poder na Embrapa. Os grandes líderes do passado já se foram e os empregados antigos, que ajudaram a construir a empresa e que ainda continuam na organização, estão aos poucos se aposentando. É uma conseqüência lógica do estágio de desenvolvimento em que se encontra, hoje, a organização. Mais madura, a Embrapa precisa reciclar-se para acompanhar as mudanças e continuar a sobreviver. A tradição e as crenças do passado vão cedendo espaço aos novos valores que vão surgindo e que também são importantes para a organização. É o fim da adolescência e o começo de fase mais adulta, estável e equilibrada, quando a nova personalidade da organização emerge e toma forma.

\section{A Embrapa como Organizaçăo Meritocrática}

Mintzberg (1983), ao explicar os diferentes estágios da vida organizacional com base nas configurações de poder, defende que as organizações missionárias que sobrevivem geralmente se tornam sistemas fechados ou meritocracias. A condição chave que faz surgir uma configuração de poder do tipo meritocracia é a necessidade de a organização desempenhar um trabalho complexo, o qual requer alto nível de especialização na sua coalizão interna.

A história relata que uma das grandes falhas que provocou o fracasso de todas as tentativas de reforma do sistema agrícola brasileiro, que precederam a criação da Embrapa, ocorreu no aspecto fundamental da pesquisa - a falta de apoio ao pesquisador (o especialista). Não foram instituídos mecanismos adequados para a administração dos recursos humanos especializados. Por isto a pesquisa de nível federal não podia concorrer no mercado de trabalho e obter o concurso dos melhores talentos. Era preciso valorizar o pesquisador e essa valorização ocorreu, de fato, com a criação da Embrapa. Na estrutura da Embrapa, quem detém, realmente, a maior parcela de poder é o pesquisador, integrante do grupo ocupacional técnico-científico responsável pela atividade-fim da empresa. O poder do pesquisador surge em função do seu conhecimento especializado, o qual é essencial ao funcionamento da organização. Assim, dentro da tipologia proposta por Mintzberg (1983), a Embrapa se caracterizaria como tendo uma configuração de poder meritocrática, o poder é distribuído em função do mérito, com uma coalizão interna profissional.

\section{A Embrapa como Organização Missionária/Meritocrática}

Mas, se a Embrapa é formada por um grupo dominante de especialistas (o pesquisador técnico-científico), como explicar o fato de que a configuração de 
poder com média mais alta foi a missionária e não a meritocracia? A resposta poderia estar na própria história da fundação da empresa.

No Brasil, na época da implantação da Embrapa, o número de pesquisadores das áreas de ciências agrárias e afins com formação de Mestrado e Doutorado era extremamente reduzido. Essa falta de pessoal especializado no mercado de trabalho fez com que a empresa contratasse grande parte do seu pessoal técnico diretamente nas portas das universidades brasileiras. Todo esse contingente de jovens profissionais foi imediatamente incorporado ao programa de pós-graduação que a empresa organizou especificamente para suprir essa deficiência. Esse quadro gerou conseqüências importantes, como, por exemplo: 1) muitos dos profissionais que compõem o quadro técnico da empresa tiveram na Embrapa a oportunidade do seu primeiro emprego; 2) além do emprego, eles tiveram a oportunidade de aprimorar os seus conhecimentos técnicos nos melhores e mais bem conceituados centros de ensino, localizados tanto no país quanto no exterior; 3 ) esses profissionais não chegaram à organização trazendo uma especialização específica, mas tiveram talhadas as suas especializações em função dos interesses e objetivos da empresa.

No entendimento desta autora, essas conseqüências podem ter contribuído na formação de uma coalizão interna profissional impregnada de fortes conotações ideológicas. O conjunto de circunstâncias que envolveu a contratação desse grupo de especialistas teria gerado um sentimento de lealdade para com a organização (fator essencial na configuração missionária) em função: a) do fato de ter sido a Embrapa a primeira organização (ou uma das primeiras) em que esses profissionais trabalharam; b) do fato de ter sido a Embrapa a instituição que propiciou a complementação da formação profissional desses funcionários e c) da participação que esses profissionais tiveram no processo de formação e desenvolvimento da organização. Assim, as circunstâncias peculiares que cercaram a criação da Embrapa e os seus primeiros anos de vida teriam propiciado o surgimento de algumas condições necessárias à emergência de uma configuração de poder do tipo missionária.

Entretanto a empresa tende a assumir uma configuração de poder que lhe é mais característica - a meritocracia. Indícios fortes que revelam o andamento dessa transição entre configurações podem ser observados em muitas ações que caracterizam a Embrapa dos dias atuais. O processo de contratação do pessoal técnicocientífico, que prevalece atualmente na organização, é um bom exemplo dessa mudança. Ao contrário do que ocorreu no passado, os profissionais recém-entrados no mercado de trabalho possuem poucas chances de serem contratados hoje pela Embrapa. Em seus concursos públicos, a empresa tem priorizado a contratação de profissionais com nível maior de experiência e que já sejam detentores de títu- 
los de pós-graduação. É uma nova geração de especialistas que vem substituir, gradualmente, a primeira geração de pesquisadores, que formou o quadro de pessoal da Embrapa.

\section{Conclusóes}

Conforme foi colocado na parte introdutória deste artigo, o estudo das relações de poder permite, entre outras coisas, que se esboce um perfil da organização com benefícios diretos para várias áreas, entre elas a da tomada de decisão organizacional.

Apesar do caráter exploratório da pesquisa, os resultados encontrados, com base nas cinco configurações de poder estudadas, permitem o relato de algumas conclusões que poderiam servir de subsídios à Embrapa para futuras reflexões e/ ou intervenções:

- Configuração de Poder Missionária. Com a mudança de configuração de poder, saindo de missionária para meritocrática, a Embrapa perderá dois grandes aliados: a lealdade incondicional dos seus membros para com a organização e a sua total identificação com os objetivos e missão organizacionais, uma vez que estas são as principais características de uma configuração de poder do tipo missionária. Isso significa que, como organização meritocrática, a Embrapa deverá se preocupar mais em buscar mecanismos que visem a estimular e desenvolver esses sentimentos em seus novos empregados.

. Configuração de Poder Meritocrática. É importante observar que, em organizações desse tipo, os especialistas (no caso os pesquisadores técnico-científicos) não se submetem aos administradores, uma questão que deve ser seriamente considerada todas as vezes em que a empresa pretender introduzir mudanças no seu modus operandi ou implantar novos procedimentos. É fundamental negociar com os especialistas e argumentar sobre a adequação de novas ações que se queira implantar.

. Configuração de Poder Sistema Fechado. Essa configuração recebeu a terceira maior média por parte dos respondentes da pesquisa. A exemplo da meritocracia, a presença deste tipo de configuração também representa uma fase mais madura da organização; entretanto ela pressupõe a existência de atividades menos complexas e, principalmente, sofre menos pressões externas. Esse resultado poderia estar indicando que alguns empregados da Embrapa desconhecem ou ignoram as pressões a que a Empresa está sujeita. Esclarecêlos de que a Embrapa possui uma configuração de poder do tipo meritocrática, 
e não de sistema fechado, mostraria que ela não é uma organização tão poderosa ou independente, e sim que sofre pressões e limitações por parte dos seus influenciadores externos. Esse entendimento poderia gerar reflexos positivos, minorando o grau de reivindicações de alguns empregados, facilitando negociações e influindo no nível de satisfação do trabalhador.

. Configuração de Poder Autocracia. Os respondentes também consideraram este tipo de configuração aplicável à Embrapa (quarta maior média). A variável independente cargo foi a melhor prognosticadora para a variável dependente autocracia, indicando que os empregados do grupo Suporte à Pesquisa (atividade-meio) percebem essa configuração como mais aplicável à empresa do que os empregados do grupo Técnico-Científico (atividade-fim). Isto poderia ser o reflexo da concentração do poder nas mãos dos especialistas, fazendo com que os empregados não ocupantes do cargo de Pesquisador se sintam trabalhando sob um regime autocrático de poder.

. Configuração de Poder Instrumento Partidário. A média mais baixa $(2,58)$, indicou que os empregados acreditam que esse tipo de configuração seja pouco aplicável à Embrapa. Isso poderia estar sinalizando que a empresa tem conseguido desempenhar suas atividades com certa tranqüilidade, buscando atingir os objetivos que se propõe e procurando cumprir a missão para a qual foi criada. Aparentemente, não existem ainda indícios de que seus empregados estejam mais preocupados em atender os seus objetivos pessoais em detrimento dos da organização, nem que a empresa esteja servindo de instrumento para o alcance de objetivos estabelecidos pelos seus influenciadores externos, que buscam controlá-la.

\section{Considerações Finais}

Embora este estudo tenha tido caráter explorátorio e os resultados da pesquisa se restrinjam especificamente à amostra estudada (o método stepwise para análise de regressão não permite generalizações), foi possível fazer um diagnóstico da organização mediante o estudo das relações de poder encontradas.

Entre os vários modelos oferecidos pela literatura especializada, optou-se pela aplicação do modelo proposto por Mintzberg (1983). É importante salientar, todavia, que segundo o autor, a teoria das configurações de poder descreve tipos puros, caricaturas ou simplificações da realidade e, assim, nenhuma situação real de poder se irá encaixar exatamente em um desses tipos; se a tipologia proposta provar ter algum valor, muitas situações irão lembrar uma ou outra das configurações por ele criadas. 
É prudente e oportuno que outras pesquisas sejam realizadas, tanto no âmbito da Embrapa como de outras organizações, para que se possa comprovar, cientificamente, a utilidade da tipologia de Mintzberg (1983). Não se pode deixar de registrar, todavia, que embora restritos, os resultados encontrados tendem a atestar a riqueza e a coerência teórica do modelo proposto pelo autor para descrever e explicar o fenômeno do poder nas organizações.

\section{Notas}

* Artigo extraído da dissertação apresentada ao Instituto de Psicologia da Universidade de Brasília, como requisito parcial para a obtenção do título de Mestre em Psicologia Social e do Trabalho. Apresentado no XXI ENANPAD, realizado em 1997, em Angra dos Reis.

\section{ReferênCIAS Bibliográficas}

BACHARACH, S. B.;

LAWLER, E. J.

Power and politics in organizations. London: JosseyBass, 1982.

BASTOS, A. V. B.

Comprometimento no trabalho: a estrutura dos vínculos do trabalhador com a organização, a carreira e o sindicato. Brasília, 1994. Tese (Doutorado em Psicologia)Instituto de Psicologia, Universidade de Brasília, 1994.

IBARRA, H.;

ANDREWS, S. B.

Power, social influence, and sense making : effects of network centrality and proximity on employee perceptions. Administrative Science Quarterly, v. 38, p. 277-303, 1993.

MINTZBERG, $\mathrm{H}$.

Power in and around organizations. Englewood Cliffs, NJ : Prentice-Hall, 1983.

PAGÈS, M. et al.

O poder das organizações - a dominação das multinacionais sobre os indivíduos. São Paulo : Atlas, 1987.

PAZ, M. G. T. DA

Avaliação de desempenho ocupacional e estruturas de poder. IN: TAMAYO, A.; BORGESANDRADE, J. E.; CODO, W. (Eds.). Trabalho, organizações e cultura. Brasília : ANPEPP, 1996. 1. v.

PETTIGREW, A.;

MCNULTY, T.

Power and influence in and around the boardroom. Human

Relations, v. 48, n. 8, p. 845-874, 1995.

PFEFFER, J.

Power in organizations. New York : HarperBusiness, 1981. 